\title{
SAZONALIDADE DOS EPISÓDIOS DE ENCHENTES OCORRIDOS NA BACIA HIDROGRÁFICA DO RIO CAÍ - RS, E SUA RELAÇÃO COM A ATUAÇÃO DO FENÔMENO EL NIÑO, NO PERIOdO DE 1982 A 2005
}

\author{
Cássio Arthur Wollmann ${ }^{14}$ \\ Maria da Graça Barros Sartori ${ }^{15}$
}

\begin{abstract}
RESUMO
O fenômeno "El Niño" exerce uma considerável influência sobre o clima do Rio Grande do Sul em determinados anos, especialmente sobre os totais pluviométricos registrados no Estado, dado que, em função do fortalecimento do Anticiclone do Atlântico, ocorre o barramento do deslocamento de frentes polares, permanecendo estes sistemas atmosféricos estacionados sobre o Rio Grande do Sul por alguns dias, favorecendo, às vezes, a formação de enchentes. No Rio Grande do Sul, tais fenômenos naturais já são conhecidos pela população, em especial, àquelas que habitam os vales dos principais rios sul-rio-grandenses, como o Rio Caí. Com isso, objetivo geral da pesquisa constituiu-se em estabelecer a sazonalidade das enchentes ocorridas na Bacia Hidrográfica do Rio Caí, no período de 1982 a 2005, calculando-se a porcentagem de ocorrência das enchentes mês a mês e estação a estação do ano, bem como avaliar, estatisticamente, a relação existente entre a ocorrência dos eventos El Niño e a ocorrência de enchentes na referida bacia hidrográfica no mesmo recorte temporal. Assim, evidenciou-se um maior número de ocorrência de enchente no inverno ( $50 \%$ do total de casos estudados), o que reflete a ocorrência de intensas frontogêneses e centros de ação mais fortalecidos na gênese das enchentes. Ao final, observou-se que o fenômeno El Niño não possui influência positiva sobre a gênese das enchentes no Rio Caí, dado que em apenas $25 \%$ dos casos houve relação.
\end{abstract}

Palavras-chave: Enchentes, Estações do ano, El Niño, Rio Grande do Sul.

\begin{abstract}
The phenomenon "El Niño" exercises a considerable influence on the climate of Rio Grande do Sul in certain years, especially on the totals of rain registered in the State, especially, in function of the invigoration of the Anticyclone of Atlantic Ocean, favoring a relative stopped of the polar fronts, staying these atmospheric

\footnotetext{
${ }^{14}$ Geógrafo/UFSM-RS/Pós-Graduando Geografia Física USP - cassio_geo@yahoo.com.br

${ }^{15}$ Prof. Dra. /Depto. Geociências/UFSM-RS - magracas@smail.ufsm.br
} 
systems stationeries on Rio Grande do Sul by some days, favoring, sometimes, the formation of inundations. In Rio Grande do Sul, the inundations have been considered as a natural phenomenon already known by the population, especially, those have inhabited the valleys of the principal rivers of State, as River Caí. In that sense, this research concerned of calculating the percentage of occurrence of the inundations in each season and month of the year in referred river in order to settle down seasonality and linking the genesis of the inundations with the occurrence of phenomena El Niño in the period from 1982 to 2005. Like this, a larger number of inundation occurrences were evidenced in the winter ( $50 \%$ of the total of studied cases), what reflects the occurrence of intense cold fronts and action centers more strengthened in the genesis of the inundations. At the end, it was observed that the phenomenon El Niño doesn't possess positive influence on the genesis of the inundations in River Caí, given that there was relationship in only $25 \%$ of the cases.

Key-words: Inundations, Seasons, El Niño, Rio Grande do Sul.

\section{INTRODUÇÃO}

No Rio Grande do Sul, as enchentes constituem-se em fenômenos naturais já conhecidos pela população, em especial, àquelas que habitam os vales dos principais rios sul-rio-grandenses. Entretanto, os estudos científicos a cerca das enchentes, em qualquer âmbito geográfico, ainda podem ser considerados pouco expressivos quanto à quantidade de trabalhos realizados e observados nos últimos congressos brasileiros.

Nesse sentido, sobre a gênese das precipitações no Estado, conforme Sartori (1979, 1980, 1993, 2003), as chuvas têm sua origem ligada às correntes perturbadas de Sul (Frentes Polares), e de Oeste (Instabilidades Tropicais), com um fortíssimo predomínio das primeiras sobre as segundas. Assim, os volumes de chuvas produzidos pelas frentes polares são muito superiores aos provocados pelas instabilidades tropicais, o que submete a ocorrência de enchentes no Estado ao domínio dos sistemas frontais, e provavelmente no inverno, em função da melhor caracterização das massas de ar polares em confronto com as de origem tropical, que intensificam o processo frontogenético e elevam, em alguns casos, os índices pluviométricos, denotando aparente sazonalidade às enchentes no Rio Grande do Sul.

Constatando-se, ainda, a influência dos eventos de "El Niño" sobre o Rio Grande do Sul em determinados anos, sabe-se que este fenômeno, cuja origem está ligado ao aquecimento superficial das águas do Oceano Pacífico Central, dá-se sobre os totais pluviométricos do Estado, intensificando-os em função do fortalecimento do Anticiclone do Atlântico, que barra o deslocamento de frentes polares, permanecendo estes sistemas atmosféricos estacionados sobre o Rio Grande do Sul por alguns dias, favorecendo a formação de enchentes.

Com isso, objetivo geral da pesquisa constituiu-se em estabelecer a sazonalidade das enchentes ocorridas na Bacia Hidrográfica do Rio Caí, no período de 1982 a 2005, calculando-se a porcentagem de ocorrência das enchentes mês a mês e estação a estação do ano, bem como avaliar, estatisticamente, a relação existente entre a ocorrência dos eventos El Niño e a 
ocorrência de enchentes NE referida bacia hidrográfica no mesmo recorte temporal.

\section{LOCALIZAÇÃO DA ÁREA DE ESTUDO}

A área de estudo selecionada para esta pesquisa compreendeu a Bacia Hidrográfica do Rio Caí, localizada na porção Nordeste do Estado do Rio Grande do Sul (Figura 01), cujas nascentes estão localizadas à altitudes próximas a 1100 m, e as áreas próximas à foz encontram-se praticamente ao nível do mar.

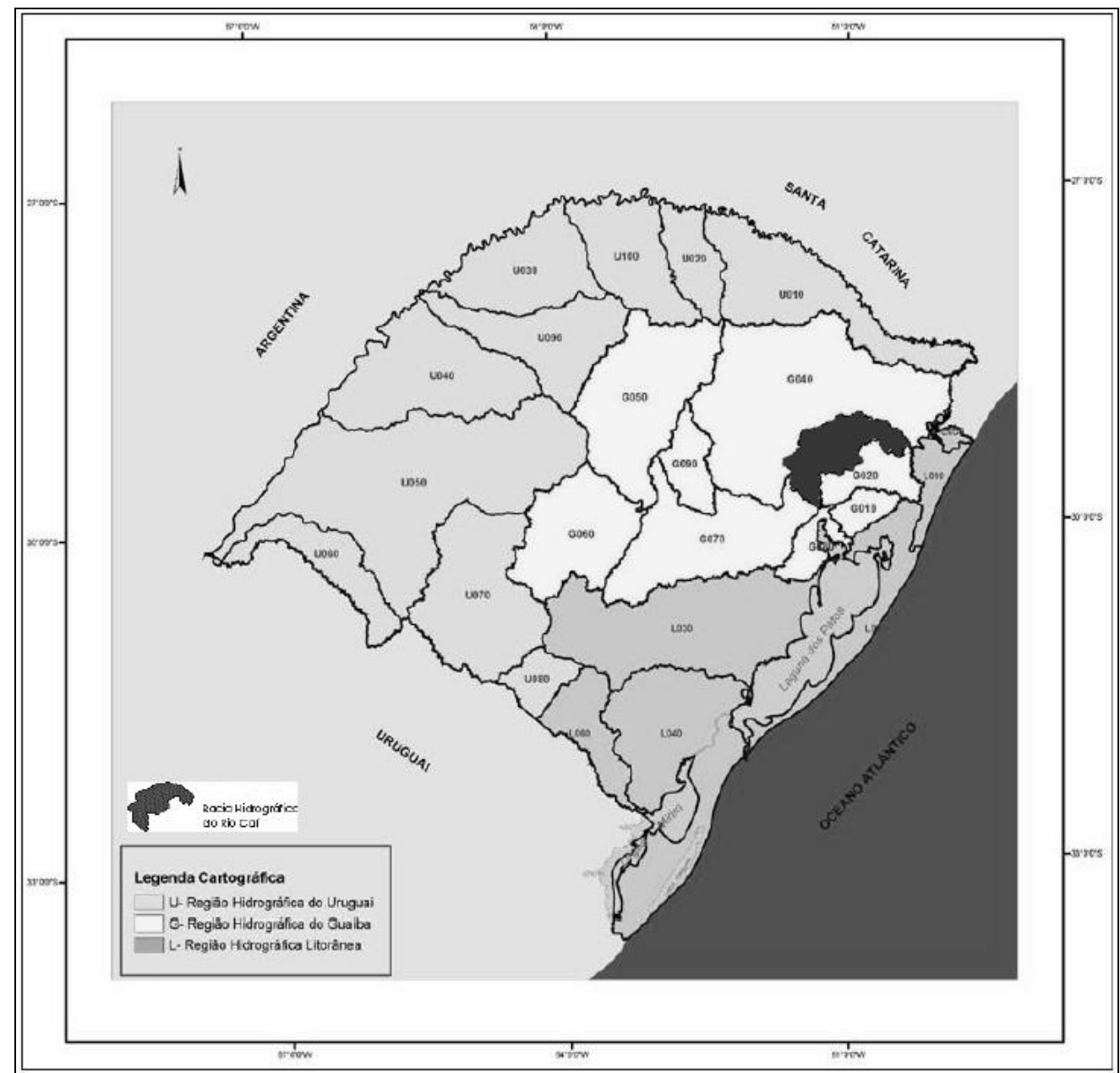

Figura 01. Localização da área de estudo, ressaltando as características hidrográficas do Rio Grande do Sul.

Fonte: SEMA (2006).

Org.: WOLLMANN, C. A., 2010.

Possui como bacias hidrográficas limítrofes a sul a Bacia Hidrográfica do Baixo-Jacuí; a leste a Bacia Hidrográfica do Rio dos Sinos; e a oeste e norte, a Bacia Hidrográfica do Taquari-Antas. Ao total, a bacia do Rio Caí possui uma área de $5.057,25 \mathrm{~km} 2$, atingindo 41 municípios gaúchos, com seus territórios total e parcialmente inseridos na bacia. 
O Rio Caí nasce no município de São Francisco de Paula com o nome de Santa Cruz. Na altura do arroio dos Macacos, ainda no referido Município, passa a chamar-se Rio Caí. Banha os municípios de São Francisco de Paula, Caxias do Sul, Nova Petrópolis, Vale Real, Feliz, Bom Princípio, Harmonia, São Sebastião do Caí, Pareci Velho, Capela de Santana, Montenegro e Nova Santa Rita, numa extensão de 268 quilômetros, até desembocar no Rio Jacuí.

A rede hidrográfica é constituída pelo Rio Caí e seus principais afluentes, dentre eles o Rio Cadeia (maior afluente), Arroio Bonito, Arroio Piaí, Arroio Forromeco, Arroio Pinhal, Arroio Santa Lúcia, Arroio do Ouro, Arroio Tapera, Arroio Maratá, Arroio Três Mares, Arroio Mineiro e Arroio Paraíso.

A ocupação inicial do Nordeste do Estado era por índios do grupo Jê. Mais tarde, deu-se através dos tropeiros e suas viagens para levar o gado do Sul para o Sudeste do Brasil entre os séculos XVII e XVIII. As colonizações com os imigrantes aconteceriam apenas a partir do início do século XIX, primeiramente com os alemães, ocupando as áreas de várzea e fundando cidades importantes, como Montenegro em 1873 e São Sebastião do Caí em 1875. Posteriormente, com a chegada dos imigrantes italianos, que ocuparam as encostas e topos dos morros da bacia, fundando cidades importantes no contexto estadual, como Caxias do Sul em 1890.

A economia presente em grande parte dos municípios que compõem a bacia do Rio Caí assenta-se sobre os três setores: agropecuária, indústria, e serviços. Na produção agrícola, destaca-se a produção de frutas, especialmente os cítricos, morangos e amoras; o milho está entre os grãos mais produzidos na bacia, destacando-se nas áreas próximas à foz do Rio Caí a produção de arroz irrigado. Já na criação de animais, as aves para produção de carne e ovos são as que mais se destacam, seguidas pela criação de suínos e bovinos.

O setor industrial é considerado o mais diversificado do Estado, e um dos principais pólos industriais do Brasil, especialmente no Município de Caxias do Sul, com a presença de indústrias do tipo metal-mecânico. Também são encontradas indústrias pequenas e médias, como as malharias da Serra Gaúcha e indústrias de beneficiamento de alimentos, sejam de origem animal ou vegetal. O setor terciário é destacado pela presença dos mais variados serviços, tais como atacados e varejos, serviços médicos especializados, bem como a região concentra a maior parte do turismo realizado no Estado, especialmente nas cidades de Gramado e Canela.

No que se refere às características naturais da área de estudo, a bacia hidrográfica possui altitudes próximas ao nível de mar ( 0 a 20 metros), até próximo dos 1000 metros de altitude nas nascentes dos rios que a compõem. Em função deste alto gradiente altimétrico, sua parte mais baixa apresenta características climáticas, conforme a classificação de Köppen, do clima tipo "Cfa", enquanto que sua parte mais elevada, situada no topo do Planalto da Bacia do Paraná, possui caracterização climática do tipo "Cfb" (Ayoade, 2003). Assim, no topo da bacia, são registrados índices pluviométricos superiores quando comparados com os índices registrados nas áreas próximas à foz do Rio Caí, com totais equivalentes a $1850 \mathrm{~mm}$ e $1350 \mathrm{~mm}$ anuais, respectivamente.

Ainda, a Bacia Hidrográfica do Rio Caí está inserida em dois compartimentos geomorfológicos do Rio Grande do Sul: a Depressão Periférica e - Planalto da bacia do Paraná. Também é significativo número de morros testemunhos na bacia, resultado do recuo da escarpa ao longo de milhões de anos pela erosão Para melhor ressaltar as condições topográficas da bacia, a Figura 02 mostra um perfil topográfico de três seções da bacia. 


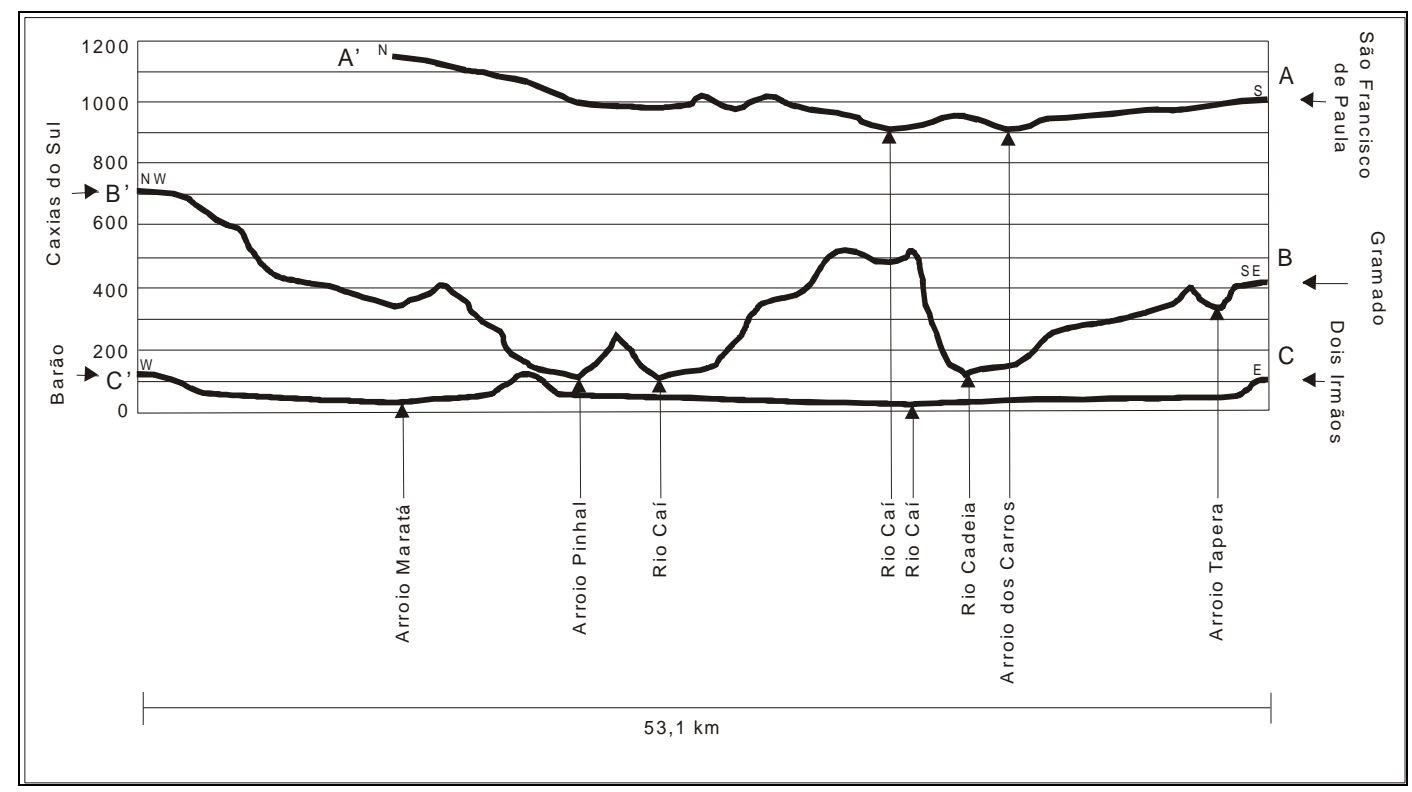

Figura 02. Perfis topográficos de três seções da Bacia Hidrográfica do Rio Caí. Org.: WOLLMANN, C. A., 2010.

As formações rochosas mais comuns encontradas na bacia são as rochas vulcânicas da Formação Serra Geral, localizadas nas partes mais altas da bacia. Também são encontradas as rochas areníticas da Formação Botucatu, encontradas principalmente nas áreas de rebordo do planalto. Ainda, nas áreas de várzea, onde as declividades são menores, são encontradas rochas quaternárias, formadas, principalmente por depósitos aluvionares. Para melhor ressaltar as feições geomorfológicas e geológicas da área de estudo.

\section{MATERIAIS E MÉTODOS}

Pesquisou-se sobre o número e meses nos quais houve ocorrência deste fenômeno na Bacia Hidrográfica do Rio Caí junto às prefeituras municipais e veículos de informação (jornais regionais), cujos meses e anos de ocorrência podem melhor ser visualizados na Tabela 01.

Para a contagem do número de ocorrências de enchentes no Rio Caí, mensal e sazonalmente, foram aplicados cálculos de freqüência mensal e sazonal das enchentes, procedimento muito usual e bem conhecido na Climatologia. Primeiramente foram catalogadas as enchentes quanto aos meses de sua ocorrência, a fim de se saber qual o mês que mais concentrou o número de enchentes no período de 1982 a 2005.

Para investigar a relação entre a ocorrência de eventos El Niño e a de episódios de enchentes na Bacia Hidrográfica do Rio Caí, fez-se apenas uma análise da relação entre os anos nos quais foram registrados o fenômeno e os anos em que foram identificadas as enchentes na referida região, bem como os anos com ocorrência de enchentes, mas sem influência do fenômeno El Niño. Também, procurou-se investigar quando havia atuação do referido fenômeno, mas não foi registrada nenhuma enchente. 
Entretanto, sabe-se que o fenômeno El Niño não á atuante durante todo o ano, mas apenas em alguns meses, e de determinados anos. Nesse sentido, relacionaram-se apenas os anos nos quais foi registrada enchente bem como se registrou El Niño como fenômeno "Forte", aplicando-se o Índice de Oscilação Sul.

Tabela 01 - Episódios de enchentes ocorridas na Bacia Hidrográficas do Rio Caí/RS, no período de 1982 a 2005.

\begin{tabular}{ccc}
\hline Ano & Mês & Dia de ocorrência \\
\hline 1982 & Junho & 28 \\
\hline 1984 & Junho & 20 \\
\hline 1986 & Dezembro & 26 \\
\hline 1988 & Setembro & 16 \\
\hline 1991 & Junho & 06 \\
\hline 1993 & Janeiro & 18 \\
\hline 1996 & Janeiro & 17 \\
\hline 1997 & Agosto & 22 \\
\hline 1997 & Outubro & 06 \\
\hline 2000 & Outubro & 13 \\
\hline 2001 & Julho & 21 \\
\hline 2001 & Setembro & 15 \\
\hline 2002 & Junho & 13 \\
\hline 2003 & Fevereiro & 21 \\
\hline 2003 & Julho & 10 \\
\hline 2005 & Agosto & 31 \\
\hline
\end{tabular}

Fonte: Prefeitura Municipal de São Sebastião do Caí/RS.

Org.: WOLLMANN, C. A., 2010.

Após isso, calculou-se a porcentagem de registros de enchentes que não estavam sobre influência do fenômeno El Niño e daquelas enchentes extraídas após uso do IOS, tendo-se, então, a real relação entre eventos El Niño e Enchentes na Bacia Hidrográfica do Rio Caí.

\section{RESULTADOS E DISCUSSÃO}

\section{Da sazonalidade das enchentes}

Após analisados os tipos de sucessão do tempo responsáveis pela gênese das enchentes na Bacia Hidrográfica do Rio Caí, partiu-se para a análise da ocorrência das enchentes, sazonal e mensalmente.

Para tal, conforme relatado nas fórmulas 1 e 2, explicitando a metodologia empregada, os resultados encontrados na análise da ocorrência mensal estão melhor dispostos conforme mostra a Tabela 02. 
Tabela 02 - Número de ocorrências mensais de enchentes na Bacia Hidrográfica do Rio Caí / RS no período entre 1982 e 2005.

\begin{tabular}{lccr}
\hline \multicolumn{1}{c}{ Mês } & Estação do Ano & $\mathbf{n}^{\circ}$ de ocorrências & Porcentagem (\%) \\
\hline Janeiro & Verão & 2 & 12,5 \\
\hline Fevereiro & Verão & 1 & 6,3 \\
\hline Março & Outono & 0 & 0,0 \\
\hline Abril & Outono & 0 & 0,0 \\
\hline Maio & Outono & 0 & 0,0 \\
\hline Junho & Inverno & 4 & 25,0 \\
\hline Julho & Inverno & 2 & 12,5 \\
\hline Agosto & Inverno & 2 & 12,5 \\
\hline Setembro & Primavera & 2 & 12,5 \\
\hline Outubro & Primavera & 2 & 12,5 \\
\hline Novembro & Primavera & 0 & 0,0 \\
\hline Dezembro & Verão & 1 & 6,3 \\
\hline Total & - & $\mathbf{1 6}$ & $\mathbf{1 0 0 , 0}$ \\
\hline Org.:WOLMANN
\end{tabular}

Org.: WOLLMANN, C. A., 2010.

Conforme mostrou a Tabela 2, das 16 ocorrências de enchentes registradas entre 1982 e 2005, 2 (duas) ocorreram no mês de janeiro, 1 (uma) em fevereiro, 4 (quatro) em junho, 2 (duas) nos meses de julho, agosto, setembro e outubro, e 1(uma) no mês de dezembro. Não foi registrada nenhuma enchente durante os meses de novembro nem durante os três meses do outono - março, abril e maio.

Uma vez aplicada a fórmula 1 , que trata da porcentagem envolvendo 0 número de ocorrências mensais das enchentes, vê-se que o mês de junho concentra a maior parte de todos os casos de registro de enchentes no Rio Caí, totalizando $25 \%$, seguido dos outros meses invernais e primaveris - julho, agosto, setembro e outubro, todos com 12,5\%. Em janeiro, já no verão, possui um valor semelhante aos meses de inverno e primavera, sendo seguido pelo mês de dezembro, com $6,3 \%$ de ocorrência.

Já durante os meses de outono, bem nos meses finais de primavera e verão (novembro e fevereiro), não houve registro de enchentes. Entretanto, cabe ressaltar que não se torna impossível a ocorrência de enchentes, especialmente nos meses de outono, pois, conforme registros históricos e fotográficos, já ocorreram enchentes durante os meses de abril e maio.

Nesse sentido, para o cálculo da porcentagem a fim de se mostrar a concentração do número de ocorrência mensal, como também o sazonal, apenas foram utilizados os casos de registro de enchentes entre os anos de 1982 a 2005, desconsiderando-se ocorrências anteriores e posteriores a este recorte temporal.

No que concerne a explicação científica para a gênese das enchentes darse com maior incidência sobre alguns meses do ano em relação a outros, tal explicação dar-se-á após explanação da Tabela 03, que mostra a ocorrência sazonal, bem como a porcentagem envolvendo o número de ocorrências sazonais das enchentes. 
Tabela 03 - Número de ocorrências sazonais de enchentes na Bacia Hidrográfica do Rio Caí/RS no período entre 1982 e 2005

\begin{tabular}{lcr}
\hline \multicolumn{1}{c}{ Estação do ano } & $\mathbf{N}^{\circ}$ de ocorrências & Porcentagem (\%) \\
\hline Primavera & 4 & 25,0 \\
\hline Verão & 4 & 25,0 \\
\hline Outono & 0 & 0,0 \\
\hline Inverno & 8 & 50,0 \\
\hline \hline Total & $\mathbf{1 6}$ & $\mathbf{1 0 0 , 0}$ \\
\hline
\end{tabular}

Org.: WOLLMANN, C. A., 2010.

De acordo com os mesmos métodos matemáticos aplicados na Tabela 02, a Tabela 03 evidencia 8 (oito) ocorrências de enchentes durante o inverno, 4 (quatro) no verão, 4 (quatro) na primavera e nenhuma durante o outono para o período 1982-2005.

Dessa forma, o número de ocorrências sazonais das enchentes, em valores percentuais, durante o inverno chega a $50 \%$, enquanto que primavera e verão possuem valores de $25 \%$ cada. O outono, por sua vez, não apresentou qualquer número de ocorrência de enchente.

Assim, visualizados os dados concentrados nas tabelas 2 e 3 e visto que as enchentes concentram-se especialmente nos meses de inverno e começo de primavera, as explicações cientificas, calcadas nos moldes da Climatologia Geográfica, que melhor explicariam essa sazonalidade invernal, mas não periodicidade, para a ocorrência de enchentes na Bacia Hidrográfica do Rio Caí é o fortalecimento dos centros de ação durante o inverno do Hemisfério Sul, especialmente do Anticiclone Polar Atlântico (APA) e do Anticiclone Tropical Atlântico (ATA), que em confronto, geram frontogêneses muito mais intensas, podendo elevar, acima do habitual, os índices pluviométricos na referida bacia hidrográfica, bem como em todo o Rio Grande do Sul (Sartori, 2003).

Entretanto, apenas as intensas frontogênses não explicariam a maior concentração das enchentes nos meses de inverno e primavera, pois, o fortalecimento dos centros de ação, tanto polares quanto tropicais, pode gerar um jogo de forças entre estes dois centros do qual ambos encontram-se extremamente fortalecidos, não ocorrendo deslocamento das massas de ar nem das frentes polares que estão ligadas às mesmas.

Desse modo, as frentes polares, na caso de não avançar para latitudes mais baixas, podem permanecer vários dias sobre o Rio Grande do Sul, elevando os índices pluviométricos em todo o Estado, especialmente no Planalto da Bacia do Paraná, em função do efeito orográfico ao qual os sistemas atmosféricos são obrigados a elevar-se, também onde estão localizadas as nascentes dos principais rios sul-rio-grandenses, dentre eles, o Rio Caí.

Ainda, em função da Massa Polar Atlântica (MPA) estar com seu gradiente barométrico horizontal fortalecido, em alguns casos, seu deslocamento dá-se de forma rápida, atraída pelas temperaturas tropicais, empurrando a frente polar situada em sua vanguarda, também de forma rápida, podendo elevar repentinamente os índices pluviométricos, dado o tempo tempestuoso, e ao sofrer o efeito orográfico pelo rebordo do planalto, tais índices podem elevar-se ainda mais, gerando uma enchente.

Em alguns casos, o ATA encontra-se mais fortalecido em relação ao APA. Desse confronto, a frente pode recuar de latitudes mais baixas em direção ao Rio Grande do Sul (como Frente Quente) e permanecer sobre o território gaúcho 110 
(como Frente Estacionária) até que a MPA tenha força suficiente para deslocar a frente novamente para latitudes tropicais, elevando os índices pluviométricos dada a precipitação acumulada de vários dias.

Na primavera, as causas para a ocorrência de enchentes, especialmente nos meses de setembro e outubro, estão ligadas ao que Sartori (op. cit.) explica como uma "re-configuração dos sistemas atmosféricos" na passagem de condições climáticas de inverno, com o Hemisfério Sul mais frio, para condições de verão, sendo a primavera uma estação de transição.

Nesta passagem, em função do gradativo aquecimento do Hemisfério Sul como um todo, em alguns casos os centros de ação ainda permanecem fortalecidos, com características invernais, gerando frontogêneses intensa pelas mesmas razões encontradas no inverno, entretanto com uma freqüência relativamente inferior (Sartori, 1980).

Na primavera, as enchentes também podem ser chamadas de "Enchentes de São Miguel", conforme relatou Rossato; Sartori; Silveira (2003), por ocorrerem no final de setembro e inicio de outubro, próximo a data de comemoração do santo de mesmo nome, quando, de fato, ocorre a reconfiguração dos sistemas atmosféricos atuantes sobre o sul do Brasil, elevando, às vezes, consideravelmente os índices pluviométricos no Rio Grande do Sul, podendo ocorrer enchentes.

Durante o verão, com o Hemisfério Sul já aquecido pela alta incidência de radiação solar e maio duração do dia, o gradiente térmico latitudinal aumenta consideravelmente, o que, de certo modo, acelera o deslocamento das massas de ar polares em direção às latitudes tropicais, já que também são impulsionadas por este gradiente, aliado ao gradiente horizontal de pressão.

Com um deslocamento mais veloz das massas de ar polares, caso estas possuam preservadas suas propriedades físicas (temperatura, pressão atmosférica e umidade), estas ainda são capazes de produzir consideráveis frontogênses que podem deslocar-se rapidamente, como Frente Fria de Deslocamento Rápido (FFDR) tal quais suas massas de ar fornecedoras de umidade, elevando os índices pluviométricos, dado o tempo tempestuoso, e aliado ao efeito orográfico do rebordo do Planalto da bacia do Paraná, aumentam ainda mais estes índices, podendo gerar enchentes.

No entanto, destaca-se que a FFDR pode acontecer em qualquer época do ano. Porém, no verão, dados os altos gradientes térmicos registrados no Hemisfério Sul, sua participação pode aumentar (Wollmann, Sartori, Ribeiro, et. al., 2007). Os casos de frentes quentes e frentes estacionárias no verão também não estão isentos, mas em função do enfraquecimento dos sistemas atmosféricos ser mais comum nesta época do ano, o confronto entre ATA e APA diminui consideravelmente.

Já no outono, mesmo não tendo ocorrido nenhuma enchente no período de 1982 a 2005, as causas que levariam à ocorrência de uma enchente nesta estação do ano seriam as mesmas da primavera: re-configuração dos sistemas atmosféricos. Entretanto, seria uma re-configuração de uma condição de verão, com o Hemisfério Sul mais aquecido, para condições invernais, com a gradativa diminuição da temperatura, fortalecendo os sistemas atmosféricos atuantes no Rio Grande do Sul.

Assim, pode-se perceber que o inverno concentra maiores opções e condições do ponto de vista dinâmico da atmosfera de ocorrer enchentes, uma vez que os centros de ação encontram-se mais fortalecidos, gerando intensas frontogêneses, que podem apresentar vários tipos de deslocamento, e como 
conseqüência, vários tipos de sucessão do tempo geradores de enchentes, especialmente na Bacia Hidrográfica do Rio Caí.

\section{Da influência do El Niño}

Dentre as escalas geográficas de clima que podem interferir na circulação atmosférica responsável pela gênese de enchente, pode-se destacar a regional, responsável pela sucessão de massas de ar e correntes perturbadas sobre uma região; e a global, responsável pela formação das grandes zonas barométricas da Terra, às quais está ligada a formação do fenômeno El Niño.

Nesse sentido, de acordo com a proposta desta pesquisa, a Tabela 04 mostra os anos nos quais foi registrada a atuação do fenômeno El Niño, no período de 1982 a 2005, bem como sua intensidade, e se houve, ou não, registro de enchente na Bacia Hidrográfica do Rio Caí, com o respectivo mês de ocorrência.

Tabela 04 - Meses e anos de ocorrência de evento El Niño Oscilação Sul (ENOS) e intensidade dos eventos no período entre 1982 a 2005.

\begin{tabular}{|c|c|c|c|}
\hline Ano & Evento & Intensidade & Registro de Enchente \\
\hline 1982 & El Niño & Forte & Junho \\
\hline 1983 & El Niño & Forte & - \\
\hline 1984 & - & - & Junho \\
\hline 1985 & - & - & - \\
\hline 1986 & El Niño & Moderado & Dezembro \\
\hline 1987 & El Niño & Moderado & - \\
\hline 1988 & El Niño & Moderado & Setembro \\
\hline 1989 & & - & - \\
\hline 1990 & El Niño & Forte & - \\
\hline 1991 & El Niño & Forte & Junho \\
\hline 1992 & El Niño & Forte & - \\
\hline 1993 & El Niño & Forte & Janeiro \\
\hline 1994 & El Niño & Moderado & - \\
\hline 1995 & El Niño & Moderado & - \\
\hline 1996 & - & - & Janeiro \\
\hline 1997 & El Niño & Forte & Agosto/Outubro \\
\hline 1998 & El Niño & Forte & - \\
\hline 1999 & - & - & - \\
\hline 2000 & - & - & Outubro \\
\hline 2001 & - & - & Julho/Setembro \\
\hline 2002 & El Niño & Moderado & Junho \\
\hline 2003 & El Niño & Moderado & Fevereiro/Julho \\
\hline 2004 & El Niño & Fraco & - \\
\hline 2005 & El Niño & Fraco & Agosto \\
\hline
\end{tabular}

Fonte: CPTEC-INPE (2007)

Org.: WOLLMANN, C. A., 2010. 
Com a ocorrência destes eventos, é sabido que o ATA fortalece-se e impede, em muitos casos, o avanço das frentes polares para latitudes mais baixas, podendo permanecer, por vários dias, sobre o território gaúcho, o que pode gerar enchente.

De acordo com a Tabela 04, no período entre 1982 a 2005, na maioria dos casos, houve registro de eventos deste tipo, predominando eventos com intensidade forte a moderada, que, em alguns casos, registrou-se enchente. Nesse sentido, a Tabela 05 mostra o número de enchentes relacionadas com os eventos El Niño e suas respectivas intensidades, bem como as enchentes ocorridas em anos neutros, e a porcentagem correspondente.

Tabela 05 - Relação entre a intensidade dos eventos El Niño e número de ocorrências de enchentes registradas na Bacia Hidrográfica do Rio Caí/RS no período entre 1982 a 2005.

\begin{tabular}{lcr}
\hline \multicolumn{1}{c}{ Evento } & $\mathbf{n}^{\circ}$ de ocorrências de enchentes & Porcentagem $\mathbf{( \% )}$ \\
\hline ENOS Forte & 5 & 31,3 \\
\hline ENOS Moderado & 5 & 31,3 \\
\hline ENOS Fraco & 1 & 6,3 \\
\hline \hline Total & $\mathbf{1 1}$ & $\mathbf{6 8 , 9}$ \\
\hline \hline Anos neutros & 5 & 31,3 \\
\hline \hline Total & $\mathbf{1 6}$ & $\mathbf{1 0 0 , 0}$ \\
\hline
\end{tabular}

Org.: WOLLMANN, C. A., 2010.

De acordo com a Tabela 05, que foi construída a partir da aplicação da fórmula 1, especificada na metodologia, percebe-se que 5 (cinco), do total de 16 (dezesseis) enchentes, ocorreram em anos cujo fenômeno El Niño estava com intensidade forte, totalizando $31,3 \%$ dos casos. Outras 5 (cinco) enchentes aconteceram em anos de intensidade moderada do fenômeno, também totalizando $31,3 \%$ das ocorrências, e apenas 1 (uma) enchente ( $6,3 \%$ do total) ocorreu em ano de fenômeno com intensidade fraca.

Nesta primeira relação, totalizou-se 11 (onze) casos de enchente ocorridos em anos com registros de atuação do fenômeno El Niño, perfazendo um total de $68,9 \%$ dos casos contra apenas 5 (cinco) enchentes ( $31,3 \%$ ) que ocorreram em anos neutros (Também foram considerados como anos neutros os anos de ocorrência do fenômeno La Niña).

Em um primeiro momento, concluir-se-ia que a ocorrência de fenômenos El Niño possui uma relação altamente positiva com as enchentes na bacia do Rio Caí. Entretanto, sabe-se que o fenômeno El Niño não possui atuação durante o decorrer de um ano civil, mas sim, em alguns meses do ano, que comumente não são os mesmos a cada manifestação do fenômeno, apesar de Berlato; Fontana (2003) afirmarem sua atuação é maior durante os meses de maio, junho, setembro, outubro e novembro.

Todavia, não é o que se constata nos dados da Tabela 06, publicada pelo NOAA/USA, que indicam o Índice de Oscilação Sul (IOS) para cada mês do ano de período entre 1982 e 2005. 
Tabela 06 - Índice de Oscilação Sul (IOS) mensal do evento El Niño para o período de 1982 a 2005

\begin{tabular}{|c|c|c|c|c|c|c|c|c|c|c|c|c|}
\hline Ano & Jan & Fev & Mar & Abr & Maio & Jun & Jul & Ago & Set & Out & Nov & Dez \\
\hline 1982 & 9,4 & 0,6 & 2,4 & $-3,8$ & $-8,2$ & $-20,1$ & $-19,3$ & $-23,6$ & $-21,4$ & $-20,2$ & $-31,1$ & $-21,3$ \\
\hline 1983 & $-30,6$ & $-33,3$ & $-28,0$ & $-17,0$ & 6,0 & $-3,1$ & $-7,6$ & 0,1 & 9,9 & 4,2 & $-0,7$ & 0,1 \\
\hline 1984 & 1,3 & 5,8 & $-5,8$ & 2,0 & $-0,3$ & $-8,7$ & 2,2 & 2,7 & 2,0 & $-5,0$ & 3,9 & $-1,4$ \\
\hline 1985 & $-3,5$ & 6,7 & $-2,0$ & 14,4 & 2,8 & $-9,6$ & $-2,3$ & 8,5 & 0,2 & $-5,6$ & $-1,4$ & 2,1 \\
\hline 1986 & 8,0 & $-10,7$ & 0,8 & 1,2 & $-6,6$ & 10,7 & 2,2 & $-7,6$ & $-5,2$ & 6,1 & $-13,9$ & $-13,6$ \\
\hline 1987 & $-6,3$ & $-12,6$ & $-16,6$ & $-24,4$ & $-21,6$ & $-20,1$ & $-18,6$ & $-14,0$ & $-11,2$ & $-5,6$ & $-1,4$ & $-4,5$ \\
\hline 1988 & $-1,1$ & $-5,0$ & 2,4 & $-1,3$ & 10,0 & $-3,9$ & 11,3 & 14,9 & 20,1 & 14,6 & 21,0 & 10,8 \\
\hline 1989 & 13,2 & 9,1 & 6,7 & 21,0 & 14,7 & 7,4 & 9,4 & $-6,3$ & 5,7 & 7,3 & $-2,0$ & $-5,0$ \\
\hline 1990 & $-1,1$ & $-17,3$ & $-8,5$ & $-0,5$ & 13,1 & 1,0 & 5,5 & $-5,0$ & $-7,6$ & 1,8 & $-5,3$ & $-2,4$ \\
\hline 1991 & 5,1 & 0,6 & $-10,6$ & $-12,9$ & $-19,3$ & $-5,5$ & $-1,7$ & $-7,6$ & $-16,6$ & $-12,9$ & $-7,3$ & $-16,7$ \\
\hline 1992 & $-25,4$ & $-9,3$ & $-24,2$ & $-18,7$ & 0,5 & $-12,8$ & $-6,9$ & 1,4 & 0,8 & $-17,2$ & $-7,3$ & $-5,5$ \\
\hline 1993 & $-8,2$ & $-7,9$ & $-8,5$ & $-21,1$ & $-8,2$ & $-16,0$ & $-10,8$ & $-14,0$ & $-7,6$ & $-13,5$ & 0,6 & 1,6 \\
\hline 1994 & $-1,6$ & 0,6 & $-10,6$ & $-22,8$ & $-13,0$ & $-10,4$ & $-18,0$ & $-17,2$ & $-17,2$ & $-14,1$ & $-7,3$ & $-11,6$ \\
\hline 1995 & $-4,0$ & $-2,7$ & 3,5 & $-16,6$ & $-9,0$ & $-1,5$ & 4,2 & 0,8 & 3,2 & $-1,3$ & 1,3 & $-5,5$ \\
\hline 1996 & 8,4 & 1,1 & 6,2 & 7,8 & 1,3 & 13,9 & 6,8 & 4,6 & 6,9 & 4,2 & $-0,1$ & 7,2 \\
\hline 1997 & 4,1 & 13,3 & $-8,5$ & $-16,2$ & $-22,4$ & $-24,1$ & $-9,5$ & $-19,8$ & $-14,8$ & $-17,8$ & $-15,2$ & $-9,1$ \\
\hline 1998 & $-23,5$ & $-19,2$ & $-28,5$ & $-24,4$ & 0,5 & 9,9 & 14,6 & 9,8 & 11,1 & 10,9 & 12,5 & 13,3 \\
\hline 1999 & 15,6 & 8,6 & 8,9 & 18,5 & 1,3 & 1,0 & 4,8 & 2,1 & $-0,4$ & 9,1 & 13,1 & 12,8 \\
\hline 2000 & 5,1 & 12,9 & 9,4 & 16,8 & 3,6 & $-5,5$ & $-3,7$ & 5,3 & 9,9 & 9,7 & 22,4 & 7,7 \\
\hline 2001 & 8,9 & 11,9 & 6,7 & 0,3 & $\underline{-0,9}$ & 1,8 & $-3,0$ & $-8,9$ & 1,4 & $-1,9$ & 7,2 & $-9,1$ \\
\hline 2002 & 2,7 & 7,7 & $-5,2$ & $-3,8$ & $-14,5$ & $-6,3$ & $-7,6$ & $-14,6$ & $-7,6$ & $-7,4$ & $-6,0$ & $-10,6$ \\
\hline 2003 & $-2,0$ & $-7,4$ & $-6,8$ & $-5,5$ & $-7,4$ & $-12,0$ & 2,9 & $-1,8$ & $-2,2$ & $-1,9$ & $-3,4$ & 9,8 \\
\hline 2004 & $-11,6$ & 8,6 & 0,2 & $-15,4$ & 13,1 & $-14,4$ & $-6,9$ & $\underline{-7,6}$ & $-2,8$ & $-3,7$ & $\underline{-9,3}$ & $-8,0$ \\
\hline 2005 & 1,8 & $-29,1$ & 0,2 & $-11,2$ & $-14,5$ & 2,6 & 0,9 & $-6,9$ & 3,9 & 10,9 & $-2,7$ & 0,6 \\
\hline
\end{tabular}

Fonte: NOAA/USA - www.noaa.gov, 2007.

Org.: WOLLMANN, C. A., 2010.

De acordo com a Tabela 6, os valores representados que se encontram sublinhados e em negrito apontam IOS negativo, significando os meses nos quais o fenômeno El Niño estava mais ativo. Entretanto, apenas os valores negativos não explicariam a maior intensidade do fenômeno, pois oscilações nos valores são normais, dada a dinâmica inerente ao fenômeno. Neste caso, os valores negativos mais extremos (entre $-10,0$ e - 35,0) foram considerados como os de máxima atividade e intensidade mensal registrada para o El Niño.

Nesse sentido, a Tabela 07 aponta os meses nos quais houve registro de enchente, apenas em anos com El Niño, relacionando-as com a intensidade registrada durante o ano de ocorrência.

Observa-se, de acordo com a Tabela 07, a ocorrência de 5 casos de enchentes em anos de El Niño forte e outras 5 enchentes em anos de El Niño moderado. Assim, das 16 enchentes ocorridas no período analisado, 10 ocorreram durante atuação deste fenômeno, totalizando 62,5\% dos casos.

No caso da enchente de junho de 1984, o IOS estava com seu valor mínimo para aquele ano, entretanto, conforme mostrou a Tabela 4, o ano de 1984 é classificado como ano neutro, não estando a gênese desta enchente ligada à ocorrência do fenômeno El Niño 
Tabela 07 - Meses e anos de ocorrência de evento El Niño e intensidade do evento na Bacia Hidrográfica do Rio Caí/RS no período entre 1982 a 2005.

\begin{tabular}{lll}
\hline Forte & Moderado & Fraco \\
\hline Junho de 1982 & Dezembro de 1986 & Agosto de 2005 \\
\hline Junho de 1991 & Setembro de 1988 & \\
\hline Janeiro de 1993 & Junho de 2002 & \\
\hline Agosto de 1997 & Julho de 2003 & \\
\hline Outubro de 1997 & Fevereiro de 2003 & \\
\hline
\end{tabular}

Org.: WOLLMANN, C. A., 2010.

Outras enchentes acontecidas em períodos de IOS negativo, como junho de 1991, janeiro de 1993, julho e setembro de 2001, junho de 2002, fevereiro de 2003 e agosto de 2005, em sua maioria, foram em anos com atuação de El Niño com intensidade moderada. Entretanto, nos meses em que houve registro da enchente, o fenômeno não se apresentava em sua maior intensidade para o respectivo ano (Tabela 6 ), estando a enchente ligada muito mais à sucessões do tempo, conforme relata Wollmann (2008).

Assim, em uma primeira análise, pôde-se concluir que as enchentes têm, em um pouco mais da metade dos casos, ligação direta com o fenômeno El Niño. Entretanto, não se pode de maneira nenhuma descartar a relação com a dinâmica atmosférica regional em consonância com as características topográfica do Rio Grande do Sul, que somadas ao fenômeno El Nino, podem acentuar a ocorrência destes episódios de enchentes.

\section{CONCLUSÕES}

A partir do momento no qual se optou por trabalhar com a temática das enchentes, especialmente as ocorridas na Bacia Hidrográfica do Rio Caí no período de 1982 a 2005, constatou-se que muitas linhas de pesquisa em Geografia têm trabalhado com esta problemática. Nesse sentido é que se optou pela Climatologia Geográfica como linha de pesquisa das enchentes, dado ao bom embasamento metodológico já existente e ao baixo índice de trabalhos sobre enchente dentro deste ramo de pesquisas.

No que concerne a proposta de estabelecer a sazonalidade das enchentes, indubitavelmente a maioria ocorreu no inverno, totalizando $50 \%$ dos casos, seguido pelas ocorridas na primavera e verão, com $25 \%$ cada. Não foi registrada nenhuma no outono para o período 1982-2005, entretanto, enchentes já ocorreram em meses de outono anteriores ao período analisado. Este fato mostra que no inverno, em função do fortalecimento dos centros de ação, tanto tropicais quanto polares, as frontogêneses são mais intensas, podendo levar à ocorrência de enchentes no Rio Grande do Sul.

Dentre os meses que mais concentraram enchentes, estão os de inverno, destacando-se junho, com $25 \%$ do total, seguido por julho e agosto $(12,5 \%)$. Os meses de primavera, especialmente setembro de outubro, concentraram $12,5 \%$ cada um, denotando a ocorrência das enchentes de São Miguel. Já os meses de verão foram os que menos registraram os eventos, exceto dezembro, com $12,5 \%$ das enchentes; janeiro e fevereiro totalizaram apenas $6,3 \%$ dos casos cada. Em relação ao fenômeno El Niño, pode-se pensar que $62,5 \%$ das enchentes estavam relacionadas à manifestação do fenômeno. 
Por fim, este estudo sobre a sazonalidade e a relação existente entre a ocorrência de enchentes na Bacia Hidrográfica do Rio Caí e sua relação com a ocorrência e intensidade do fenômeno El Niño vem sanar um pouco as lacunas existentes nos estudos deste fenômeno na referida bacia, bem como em todo o Rio Grande do Sul, pois tais conclusões podem ser estendidas para outras bacias hidrográficas do Estado dada à gênese da circulação atmosférica regional ser a mesma. Assim, esse estudo contribui humildemente para o rol de pesquisas da Climatologia Geográfica brasileira e sul-rio-grandense, servindo, portanto, como fonte teórico-metodológica que possa motivar investigações futuras.

\section{REFERÊNCIAS}

BERLATO, M. A.; FONTANA, D. C. El Niño e La Niña: impactos no clima, na vegetação e na agricultura do Rio Grande do Sul - aplicações de previsões climáticas na agricultura. Porto Alegre: Ed. da UFRGS, 2003. 110p.

\section{GUERRA, A. T.; GUERRA, A. J. T. Novo dicionário geológico}

geomorfológico. 3. ed. Rio de Janeiro: Bertrand Brasil, 2003. 652p.

MACHADO, F. P. Contribuição ao estudo do clima do Rio Grande do Sul. Rio de Janeiro: Serviço Gráfico do IBGE, 1950.

ROSSATO, P. S.; SARTORI, M. G. B.; SILVEIRA, R. D. Freqüência e probabilidade de ocorrência das "Enchentes de São Miguel". In: CONGRESSO BRASILEIRO DE AGROMETEOROLOGIA, 13., 2003, Santa Maria. Anais... Santa Maria: UFSM, 2003. 1 CD-ROM.

SARTORI, M. G. B. A dinâmica do clima do Rio Grande do Sul: indução empírica e conhecimento científico. Revista Terra Livre, São Paulo, v. 1, n. 20, p. 2749, jan./jul. 2003.

SARTORI, M. G. B. As variações pluviométricas e o regime das chuvas na região central do Rio Grande do Sul. Boletim de Geografia Teorética. n. 23. p. 7084. 1993.

SARTORI, M. G. B.; FERIGOLO, E. de F.; VALMERATE, M. M. S. As chuvas no Rio Grande do Sul e a explicação genética dos episódios de seca e enchentes no período de junho de 1979 a maio de 1985. Geografia - Ensino e Pesquisa, n. 1, p. 39-68, 1987.

SARTORI, M. G. B. A circulação atmosférica regional e as famílias de tipos de tempo identificadas na região central do Rio Grande do Sul. Ciência e Natura, n. 3, p. 101-110, 1981.

SARTORI, M. G. B. Balanço sazonário da participação dos sistemas atmosféricos em 1973, na região de Santa Maria, RS. Ciência e Natura, n. 2, p. 41-53, 1980. 
SECRETARIA ESTADUAL DE MEIO AMBIENTE. Departamento de Recursos Hídricos. $1^{\mathbf{a}}$ Etapa do Plano de Bacia do Rio Caí: Consolidação do conhecimento sobre recursos hídricos e enquadramento dos recursos hídricos superficiais - Relatório temático A2, Diagnóstico da disponibilidade hídrica. Porto Alegre, 2006a. 186p.

WOLLMANN, C. A. A gênese climática das enchentes na Bacia Hidrográfica do Rio Caí. 2008. 115p. Trabalho de Graduação (Graduação em Geografia Bacharelado) - Universidade Federal de Santa Maria, 2008.

WOLLMANN, C. A.; SARTORI, M. G. B.; RIBEIRO, A. A.; et al. Circulação atmosférica regional e os tipos de sucessão do tempo no verão do Rio Grande do Sul: análise sobre três casos típicos. In: SIMPÓSIO BRASILEIRO DE GEOGRAFIA FÍSICA E APLICADA, 12., 2007, Natal. Anais... Natal: UFRN, 2007. 1 CD-ROM. 
